\title{
THE ATMOSPHERE EXPLORER OPTICAL GLOW NEAR PERIGEE ALTITUDES
}

\author{
J-H. Yee, V. J. Abreu* and A. Dalgarno
}

Harvard-Smithsonian Center for Astrophysics

*Space Physics Research Laboratory, University of Michigan

Abstract. The altitude variation of the Atmosphere Explorer optical glow intensity suggests that two different processes are responsible for the glow. One, dominant for altitudes above $180 \mathrm{~km}$, has an emission brightness proportional to the ambient atomic oxygen density whereas the other, dominant at altitudes below $160 \mathrm{~km}$, produces an emission whose intensity is proportional to the product of the densities of any of $\mathrm{N}_{2}, \mathrm{O}_{2}$ or No. The first mechanism apparently has two components, one from the surface recombination of $\mathrm{O}$ and $\mathrm{H}$ and the other from a process similar to that producing the Shuttle glow. Unless the efficiency of the second mechanism is much enhanced on the Shuttle its contribution to the Shuttle glow is negligible.

\section{Introduction}

The existence of an optical glow associated with the Atmosphere Explorer satellites was noticed by Torr et al. [1977]. The characteristics of the glow were studied by Yee and Abreu [1982, 1983] and by Yee et al. [1984] who showed that at altitudes above about $160 \mathrm{~km}$ the glow intensity was directly proportional to the density of atomic oxygen and that if the glow is produced by metastable molecules released from the surface with thermal velocities the angular distribution of the glow was consistent with a radiative lifetime of the emitting molecules of about $5 \mathrm{~ms}$. The ratio of the intensity of the glow at $732 \mathrm{~nm}$ and $656 \mathrm{~nm}$ [Yee and Abreu, 1982] was 2.25 at altitudes between 140 and $145 \mathrm{~km}$ and 2.15 between 170 and $175 \mathrm{~km}$ [Langhoff et al., 1983]. Yee and Abreu [1983] drew attention to the laboratory studies of surface-catalyzed excitations of $\mathrm{OH}, \mathrm{NO}$ and $\mathrm{NO}_{2}$ band systems. Slanger [1983] pointed out that the intensity ratio is comparable to that observed for $\mathrm{OH}$ emission in the night airglow and suggested that the rotation-vibration bands of off are the source of the glow. Data over a more extensive spectral range [Yee and Abreu, 1983] were not consistent with the $\mathrm{OH}$ night airglow emission but Langhoff et a1. [1983] showed that the Identification of $\mathrm{OH}$ as the glow species could probably be maintained by postulating an association mechanism on the satellite surface in which the vibrational levels of $\mathrm{OH}$ are populated uniformly. Yee and Abreu [1983] had demonstrated that a marked change in the scale height of the glow intensity occurred at about $140 \mathrm{~km}$ and that the glow spectrum was slightly modified. Slanger [1983] concluded that the enhanced intensity of the glow below $160 \mathrm{~km}$ is proportional to the density of

Copyright 1985 by the American Geophysical Union.

Paper number $5 \mathrm{~L} 6601$.

0094-8276/85/005L-6601\$03.00 molecular oxygen and implied that at low a1titudes vibrationally excited $\mathrm{OH}$ is produced by a surface reaction with $\mathrm{O}_{2}$.

A similar optical glow is observed in the ram direction of the Shuttle orbiter [Banks et al., 1983] though with different spectral characterIstics and with a different spatial extent [Mende et a1., 1983, 1984, 1985; Yee and Dalgarno, 1984; Swenson et a1., 1985], Green [1984] has suggested that it arises from the recombination of nitrogen atoms into high vibrational levels of the $\mathrm{A}^{3} \Sigma_{\mathrm{u}}^{+}$state of $\mathrm{N}_{2}$ which decay sequentially to vibrational levels of the $B{ }^{3}$ state to lower vibrational levels of the $A^{g} \Sigma_{\dot{u}}^{+}$state, a mechanism postulated by Weinreb and Mannella [1969] to explain laboratory measurements of the luminescence produced by surface recombination of nitrogen atoms in the presence of small amounts of electrically discharged oxygen. Mende et al. [1985] and Swenson et al. [1985] have shown that the Shuttle glow has the spectral appearance of the $\mathrm{NO}_{2}\left({ }^{2} \mathrm{~B}_{1}\right)$ recombination continuum [Fontijn et a1., 1964; Paulsen et a1., 1970; Kenner and Ogryzlo, 1984; Kuwabara et a1., 19841, and they advocate a mechanism in which nitrogen atoms and oxygen atoms recombine on the surface to form No which then reacts further with the ambient energetic oxygen atoms.

Because surface glows may place design constraints on projected shuttle-based astronomical and atmospheric observations, it is important to understand more clearly the origins of the Atmosphere Explorer and Shuttle glows. We present here a study of the Atmosphere Explorer emission at altitudes below $160 \mathrm{~km}$. We show that after subtraction of the contribution from the high altitude atomic oxygen mechanism, the

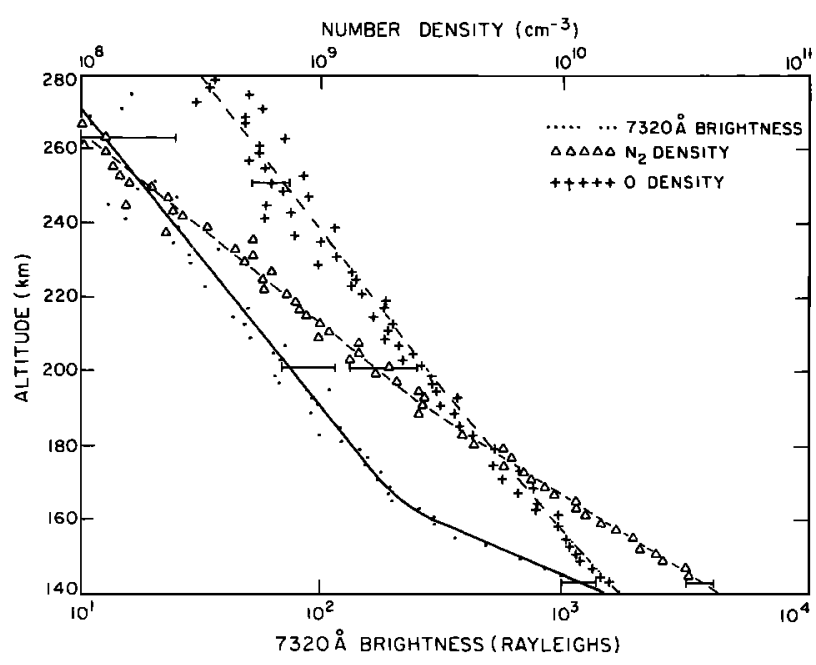

Fig. 1. The intensity of the glow at $732 \mathrm{~nm}$ in Rayleighs as a function of altitude. 


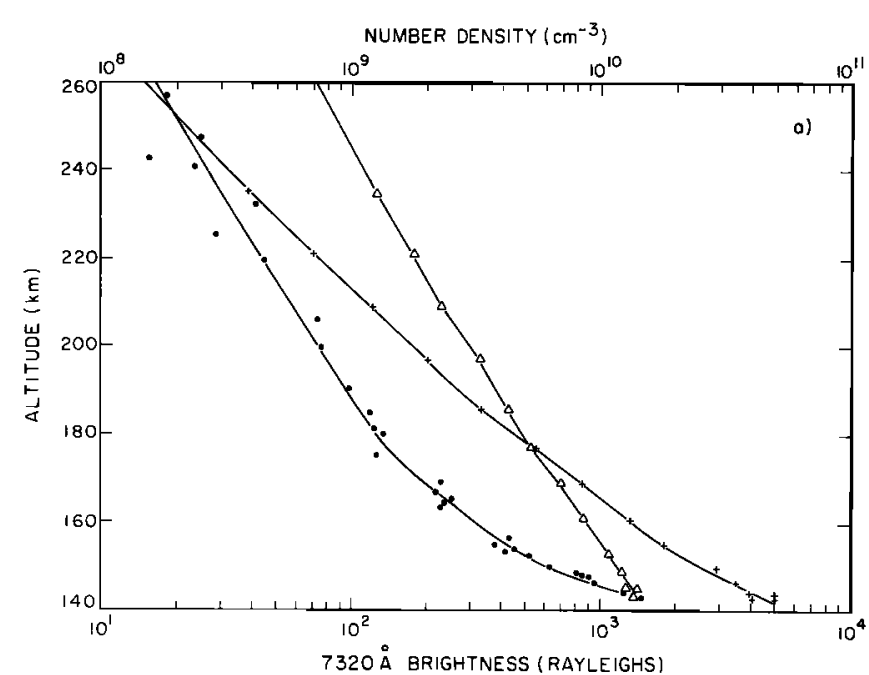

Fig. 2a. The intensity of the glow in Rayleighs, indicated by $\bullet$, and the ambient densities indicated by $\Delta$ for atomic oxygen and + for molecular nitrogen, measured on orbit 1336 .

residual emission brightness is proportional not to the density of molecular oxygen but to the product of the densities of any pair of molecular nitrogen, molecular oxygen and nitric oxide suggesting a mechanism which involves the successive collisions of two molecules.

\section{Atmosphere Explorer Glow at $732 \mathrm{~nm}$}

The intensity of the Atmosphere Explorer glow at $732 \mathrm{~nm}$ is shown in Figure 1 as a function of altitude [Yee and Abreu, 1982]. The altitude variation has two scale heights. Yee and Abreu [1983] suggested that more than one source of emission exists or that the source was timedependent.

Figures $2 \mathrm{a}$ and $2 \mathrm{~b}$ show the altitude glow and ambient density profiles obtained on orbits 1336 and 1311. At $143 \mathrm{~km}$, the intensity measured on orbit 1336 is 500 Rayleighs less than that measured on orbit 1311. The atomic oxygen densities during the two orbits were similar but

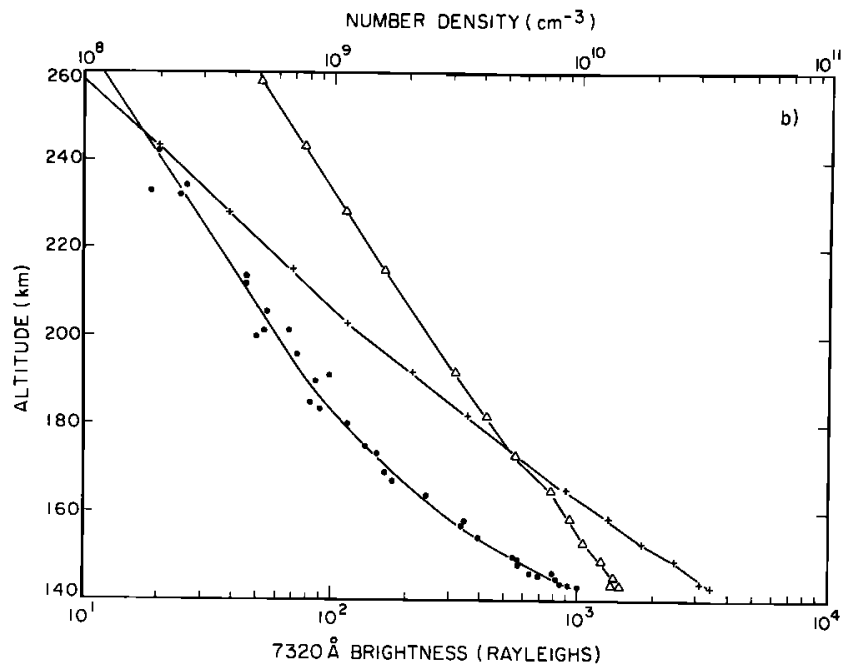

Fig. 2b. As for Fig. 2a on orbit 1331.

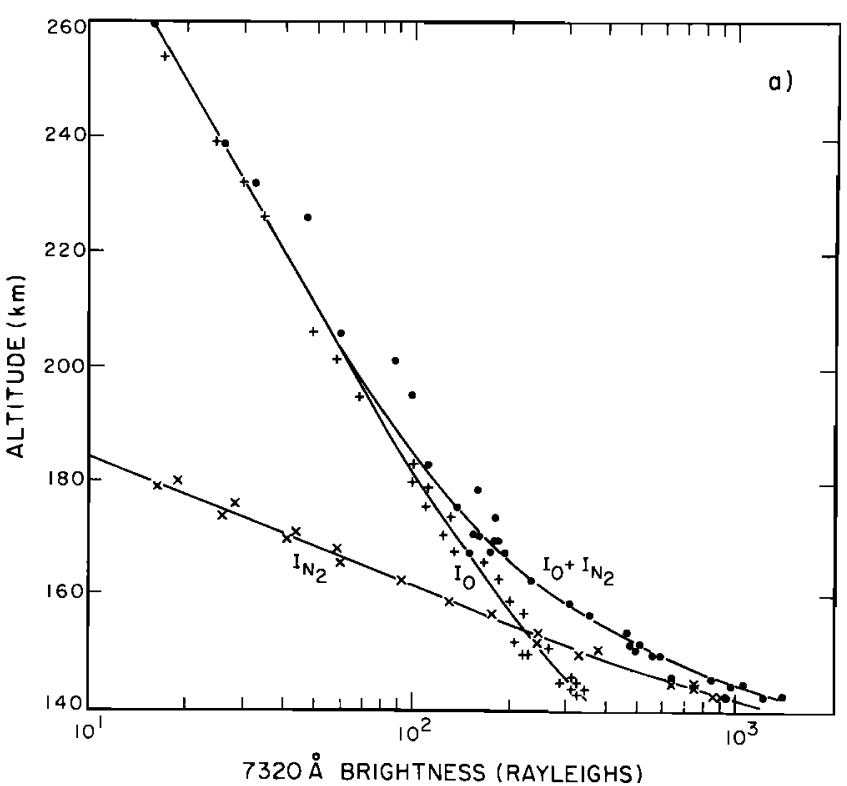

Fig. 3a. The glow intensity at $732 \mathrm{~nm}$ in Rayleighs on orbit 1336 indicated by and the separate contributions from the oxygen mechanism + and the nitrogen mechanism $x$. The fits are labelled respectively $I_{0}+I_{N_{2}}, I_{0}$ and $I_{N_{2}}$.

the molecular nitrogen densities were lower during orbit 1336 when the low altitude glow was weaker than during orbit 1311. It seems that $\mathrm{N}_{2}$ is participating in the creation of the low altitude glow though the possibilities that $0_{2}$ and No are responsible cannot be excluded if their densities varied as did the $\mathrm{N}_{2}$ density. However we will label the mechanism by $\mathrm{N}_{2}$.

The high and low altitude sources may be separated by extrapolating the high altitude brightness to low altitude using the measured atomic oxygen densities. The residual $\mathrm{I}_{\mathrm{N}_{2}}$ dominates the glow at low altitudes. Figures $3 a$ and $3 \mathrm{~b}$ show the results for orbits 1336 and 1311 .

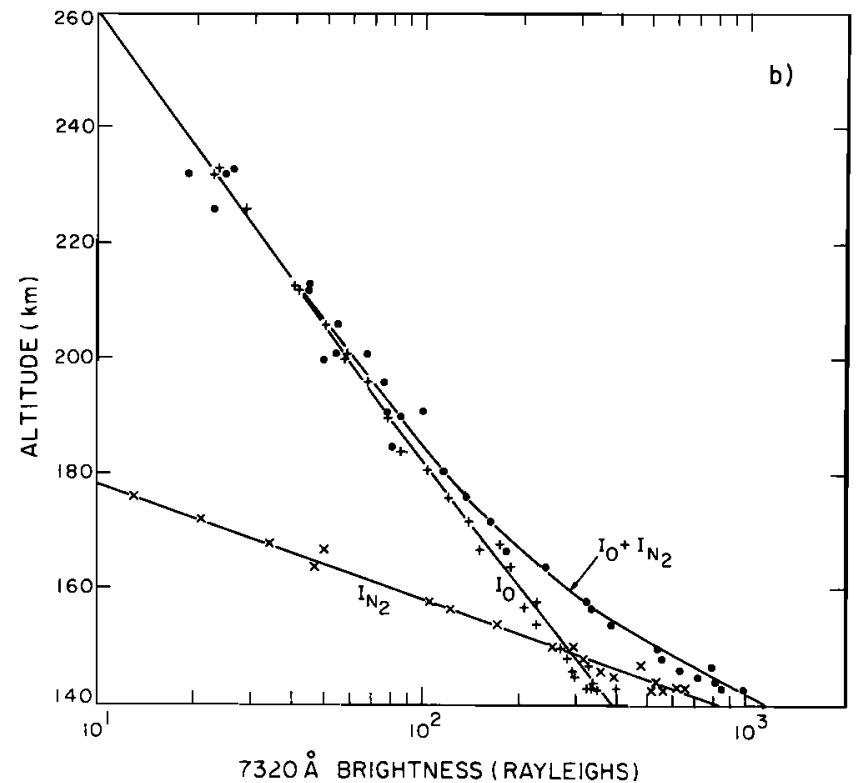

Fig. 3b. As for Fig. 3a on orbit 1311 . 


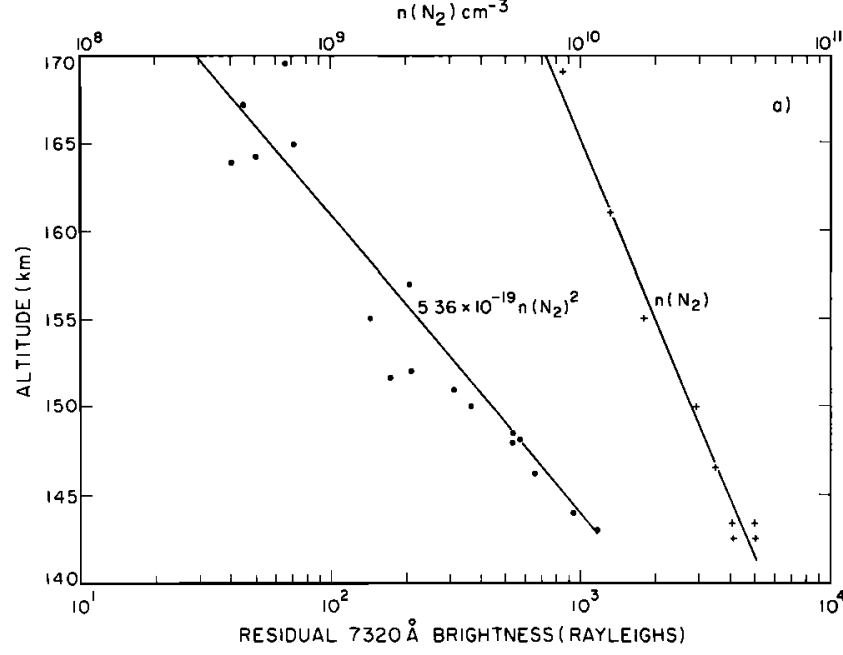

Fig. 4a. The residual brightness on Rayleighs on orbit 1336 after subtraction of the contribution proportional to [0] represented by $\bullet$ and the number density $\left[\mathrm{N}_{2}\right]$ represented by + . As indicated, the points lie approximately on the straight line $5.36 \times 10^{-19}\left[\mathrm{~N}_{2}\right]^{2}$.

We attribute $I_{\mathrm{N} 2}$ tentatively to a mechanism involving $\mathrm{N}_{2}$. Its altitude variations are compared in Figures $4 \mathrm{a}$ and $4 \mathrm{~b}$ to those of the $\mathrm{N}_{2}$ number densities. The scale heights of $\mathrm{I}_{\mathrm{N} 2}$ are equal to within measurement error to one half of those of $\mathrm{N}_{2}$ and we may write

$$
\mathrm{I}_{\mathrm{N}_{2}}=\mathrm{k}_{\mathrm{N}_{2}}\left[\mathrm{~N}_{2}\right]^{2}
$$

where $\left[\mathrm{N}_{2}\right]$ is the number density of $\mathrm{N}_{2}$ and $\mathrm{k}_{\mathrm{N} ! 2}$ is a constant. For orbit 1311,

$\mathrm{k}_{\mathrm{N} 2}=5.36 \times 10^{-19}$ Rayleighs $\mathrm{cm}^{6}$ and for orbit 1336, $\mathrm{k}_{\mathrm{N}_{2}}=5.50 \times 10^{-19}$ Rayleighs $\mathrm{cm}^{6}$. Thus the glow intensity at $732 \mathrm{~nm}$ can be reproduced over the entire range of altitudes above $143 \mathrm{~km}$ by the empirical formula

$$
I=k_{0}[0]+k_{N_{2}}\left[\mathrm{~N}_{2}\right]^{2}
$$

where [0] is the number density of 0 and $k_{0}$ is a constant. A least-squares fit to the data of six orbits yields the values

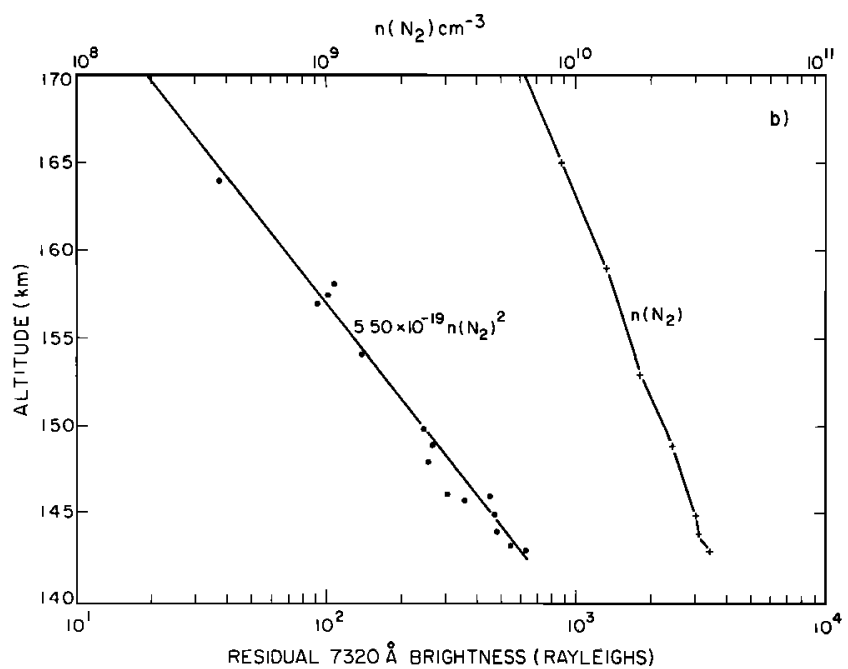

Fig. 4b. As for Fig. 4a on orbit 1311.
TABLE 1

Rate coefficients $k(\lambda)$ and $k(\lambda) / \Delta \lambda$ for 0 and $N_{2}{ }^{*}$

$\lambda(\mathrm{nm}) \quad \mathrm{k}_{0}\left(\mathrm{R} \mathrm{cm}^{3}\right) \quad \frac{\mathrm{k}_{0}}{\Delta \lambda}\left(\mathrm{R} \mathrm{cm}^{3} \mathrm{~nm}^{-1}\right)$

\begin{tabular}{lll}
\hline 732 & $2.41(-8) \pm 5.83(-10)$ & $1.07(-8) \pm 2.59(-10)$ \\
656 & $1.71(-8) \pm 3.93(-10)$ & $7.28(-9) \pm 1.75(-10)$ \\
428 & $4.25(-10) \pm 1.32(-10)$ & $2.02(-10) \pm 6.29(-11)$ \\
337 & $1.10(-9) \pm 2.37(-10)$ & $3.92(-10) \pm 8.46(-11)$ \\
280 & $1.83(-9) \pm 2.43(-10)$ & $3.32(-10) \pm 4.41(-11)$ \\
\hline & & $\mathrm{k}_{\mathrm{N}_{2}}\left(\mathrm{~cm}^{6} \mathrm{~nm}^{-1}\right)$ \\
& $\mathrm{k}_{\mathrm{N}}\left(\mathrm{R} \mathrm{cm}^{6}\right)$ & $\frac{\Delta \lambda}{4}$ \\
\hline 732 & $5.05(-19) \pm 1.66(-20)$ & $2.24(-19) \pm 7.38(-21)$ \\
656 & $4.31(-20) \pm 8.57(-21)$ & $1.83(-20) \pm 3.77(-21)$ \\
428 & $3.05(-20) \pm 1.84(-21)$ & $1.45(-20) \pm 8.76(-22)$ \\
337 & $1.08(-19) \pm 5.72(-21)$ & $3.86(-20) \pm 2.04(-21)$ \\
280 & $9.52(-20) \pm 4.26(-21)$ & $1.73(-20) \pm 7.74(-22)$
\end{tabular}

$*_{\mathrm{R}} \equiv 1$ Rayleigh $=10^{6}$ photons $\mathrm{cm}^{-2} \mathrm{~s}^{-1}$.

$$
\begin{gathered}
\mathrm{k}_{0}(732 \mathrm{~nm})=2.41 \times 10^{-8} \pm 5.83 \times 10^{-10} \\
\text { Rayleighs } \mathrm{cm}^{3} \\
\mathrm{k}_{\mathrm{N}_{2}}(732 \mathrm{~nm})=\begin{array}{c}
5.05 \times 10^{-19} \pm 1.66 \times 10^{-20} \\
\text { Rayleighs } \mathrm{cm}^{6} .
\end{array}
\end{gathered}
$$

The uncertainty of the fitting is $3 \%$ for $k_{0}$ and $\mathrm{k}_{\mathrm{N}_{2}}$.

Atmosphere Explorer Glow at Shorter Wavelengths

The photometer on board the Atmosphere Explorer satellites also provided data in wavelength bands centered at $656,520,428,337$ and $280 \mathrm{~nm}$. At the shorter wavelengths, the glow is weaker but we were able to separate out the contributions from the oxygen and nitrogen mechanisms to the emission at 656,337 and $280 \mathrm{~nm}$, though the uncertainties in the derived parameters $\mathrm{k}_{0}$ and $\mathrm{k}_{\mathrm{N}_{2}}$ are larger than for $732 \mathrm{~nm}$. For $428 \mathrm{~nm}$ and $337 \mathrm{~nm}$ simultaneous measurements of the neutral particle concentrations are not avallable and we used the data obtained on contiguous orbits. For 428,337 and $280 \mathrm{~nm}$ data were available on only one orbit.

The derived values of $k_{0}$ and $k_{N_{2}}$ and the associated uncertainties are given in Table 1 , and their ratios relative to $732 \mathrm{~nm}$ in Table 2 . Value of the rate coefficients per unit wavelength, $k_{0} / \Delta \lambda$ and $k_{N_{2}} / \Delta \lambda$, where $\Delta \lambda$ is the wavelength span of the band pass are also listed. The $\mathrm{N}_{2}$ coefficients decrease much more rapidly

TABLE 2. Intensity Ratios*

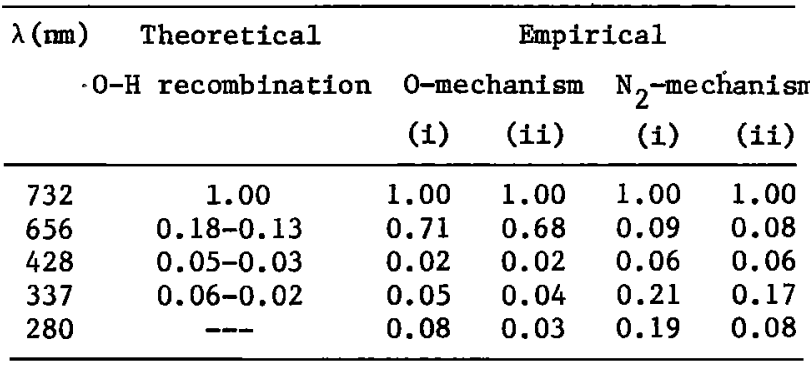

* (i) $k(\lambda) / k(732 \mathrm{~nm})$ (ii) $k(\lambda) / k(732 \mathrm{~nm}) \Delta \lambda$ 
with wavelength than the 0 coefficients giving rise to a steeper glow spectrum at low altitudes.

\section{Discussion}

In Table 2, the spectral variation of the oxygen mechanism is compared to that predicted from the surface recombination of oxygen and hydrogen atoms [Langhoff et a1., 1983]. The predicted intensity ratios and the measured values are in acceptable agreement with the exception of the $732 \mathrm{~nm} / 656 \mathrm{~nm}$ ratio. Although the predicted $732 \mathrm{~nm} / 656 \mathrm{~nm}$ ratio is particularly uncertatn because of possible contributions from the 12-5P1(5) and 14-6R1(1) lines of $\mathrm{OH}$ to the band pass at $656 \mathrm{~nm}$, the discrepancy strongly suggests that another mechanism is causing luminosity which is most intense in the region around $700 \mathrm{~nm}$. A plausible candidate is the mechanism responsible for the Shuttle glow [Mende et al., 1985; Swenson et al., 1985] and we suggest that the Atmosphere Explorer glow at high altitudes consists of two components, one arising from surface recombination of $O$ and $H$ into excited states of $\mathrm{OH}$ and the other from the Shuttle mechanism which has been attributed [Mende et al., 1985; Swenson et al., 1985] to the continuum produced by the recombination of NO and 0 .

At low altitudes a third component becomes significant. Its intensity is proportional to the square of the $\mathrm{N}_{2}$ density or equally well to the product of any pair of the densities of $\mathrm{N}_{2}, \mathrm{O}_{2}$ and NO. A variation as $\left[\mathrm{N}_{2}\right]^{2}$ is consistent with the mechanism postulated by Green [1984] though the ion mass spectrometer measurements of Engebretson et a1. [1980] on the Atmospheric Explorers do not indicate that significant dissociation of the impacting $\mathrm{N}_{2}$ molecules occurred.

It is possible that with some contribution from the second positive system at $337 \mathrm{~nm}$ the Green mechanism could reproduce the measured spectrum. At longer wavelengths, it bears some similarity to emission in the first positive system though it differs in detail from the laboratory spectrum arising from electron impact excitation [Torr and Torr, 1985]. Whatever the mechanism if it is to make a significant contribution to the Shuttle glow its efficiency $k_{N_{2}}$ must be of orders of magnitude larger for the Shuttle glow than the values we have derived for the Atmosphere Explorer satellites.

Acknowledgments. This research was supported in part by AFGL under Contract F19628-85-K-0034, by the Aeronomy Program of the National Sclence Foundation under Grant ATM-84-07314 and by NASA Grant NAGW-496 to the University of Michigan.

\section{References}

Banks, P. M., P. R. Williamson, and W. J. Raitt, Space shuttle glow observations, Geophys. Res. Lett. , 10, 118-121, 1983.

Engebretson, M. J., J. A. DeFreese, and K. Mauersberger, Diurna1, seasonal and nighttime variations of atomic nitrogen in the equatorial thermosphere, J. Geophys. Res., 85, 2165$2170,1980$.

Fontijn, A. C., C. B. Meyer, and H. J. Schiff, Absolute quantum yield measurments of the NO-0 reaction and its use as a standard for chemiluminescent reactions, J. Chem. Phys., 40, 64-70, 1964.

Green, B. D., Atomic recombination into excited molecular nitrogen - a possible mechanism for shuttle glow, Geophys. Res. Lett., 11, 576$579,1984$.

Hays, P. B., G. Carignan, B. C. Kennedy, G. G. Shepard, and J. C. G. Walker, The Visible Airglow Experiment on Atmosphere Explorer, Radio Sci., 8, 369-377, 1973.

Kenner, R. D., and E. A. Ogryzlo, Orange chemiluminescence from $\mathrm{NO}_{2}, \mathrm{~J}$. Chem. Phys., 80, $1-6,1984$.

Kuwabara, S., K. Kuwata, I. Nishiyama, and I. Hanazaki, Acoustically oscillating emissions from $\mathrm{NO}_{2}$ * produced by infrared photosensitized reaction in $\mathrm{SF}_{6}+\mathrm{NO}_{2}$, Chem. Phys. Lett., 106, $540-543,1984$.

Langhoff, S. R., R. I. Jaffe, J-H. Yee, and A. Dalgarno, The surface glow of the Atmosphere Explorer C and E satellites, Geophys. Res. Lett., 10, 896-899, 1983.

Mende, S. G., P. M. Banks, and D. A. Klingelsmith, Observations of orbiting vehicle Induced luminosities on the STS-8 mission, Geophys. Res. Lett., 11, 527-530, 1984.

Mende, S. B., O. K. Garriott, and P. M. Banks, Observations of optical emissions on STS-4, Geophys. Res. Lett., 10, 122-125, 1983.

Mende, S. B., G. R. Swenson, K. S. Clifton, R. Gause, I. Leger and 0 . K. Garriott, Space vehicle glow measurements on STS-44-D, J. Spacecraft and Rockets, in press, 1985

Paulsen, D. E., W. F. Sheridan, and R. E. Huffman, J. Chem. Phys., 53, 647-658, 1970

Slanger, T. G., Conjectures on the origin of the surface glow of space vehicles, Geophys. Res. Lett., 10, 103-132, 1983.

Swenson, G. R., S. B. Mende, and K. S. Clifton, Ram vehicle glow spectrum: implication of $\mathrm{NO}_{2}$ recombination continuum, Geophys. Res. Lett., $12,97-100,1985$.

Tor , M. R., and D. G. Torr, A preliminary spectroscopic assessment of the Spacelab 1 Shuttle optical environment, I. Geophys. Res., 90, $1683-1690,1985$.

Weinreb, M. P., and G. G. Mannella, Effect of oxygen in the surface-catalyzed excitation of nitrogen, J. Chem. Phys., 51, 4973-4979, 1969.

Yee, J-H., and V. J. Abreu, Visible glow induced by spacecraft-environment Interaction, Geophys. Res. Lett., 10, 126-129, 1983.

Yee, J-H., and A. Dalgarno, Radiative lifetime analysis of the spacecraft glows, AIAA Shuttle Environment and Operations Meeting, ALAA-03-2660-OP, 191-197, 1983.。

Yee, J-H., and V. J. Abreu, Optical contamination on the Atmosphere Explorer E-satellite, SPIE Proceedings, 338, 120-129, 1982.

Yee, J-H., V. J. Abreu and A. Dalgarno, Characteristics of the spacecraft optical glow, Geophys. Res. Lett., 11, 1192-1194, 1984.

A. Dalgarno and J-H. Yee, Harvard-Smithsonian Center for Astrophysics, 60 Garden Street, Cambridge, Mass. 02138 .

V. J. Abreu, Space Physics Research Laboratory, Unfversity of Michigan, Ann Arbor, MI 48109 .

(Received June 11, 1985; accepted July 5, 1985.) 